\title{
$\beta$ Subunits Modulate Alternatively Spliced, Large Conductance, Calcium-Activated Potassium Channels of Avian Hair Cells
}

\author{
Krishnan Ramanathan, Timothy H. Michael, and Paul A. Fuchs \\ The Center for Hearing Sciences, Department of Biomedical Engineering and Department of Otolaryngology, Head and \\ Neck Surgery, Johns Hopkins University School of Medicine, Baltimore, Maryland 21205-2195
}

\begin{abstract}
Electrical tuning confers frequency selectivity onto sensory hair cells in the auditory periphery of frogs, turtles, and chicks. The resonant frequency is determined in large part by the number and kinetics of large conductance, calcium-activated potassium (BK) channels. BK channels in hair cells are encoded by the alternatively spliced slo gene and may include an accessory $\beta$ subunit. Here we examine the origins of kinetic variability among BK channels by heterologous expression of avian cochlear slo cDNAs. Four alternatively spliced forms of the slo- $\alpha$ gene from chick hair cells were co-expressed with accessory $\beta$ subunits (from quail cochlea) by transient transfection of human embryonic kidney 293 cells. Addition of the $\beta$ subunit increased steady-state calcium affinity, raised the Hill coefficient for calcium binding, and slowed channel deactivation rates, resulting in eight functionally distinct channels. For example, a naturally
\end{abstract}

Large conductance, calcium-activated potassium (BK) channels play a prominent role in vertebrate hair cell function. BK channels in hair cells may regulate calcium flux at sites of transmitter release (Roberts et al., 1990; Issa and Hudspeth, 1994) as at the neuromuscular junction (Robitaille et al., 1993). In electrically tuned hair cells, BK channels kinetics are the principal determinant of each cell's resonant frequency (Art and Fettiplace, 1987; Hudspeth and Lewis, 1988; Art et al., 1995) and acoustic filtering (Crawford and Fettiplace, 1981). Electrical tuning frequencies vary systematically (tonotopically) along the turtle's basilar papilla (Crawford and Fettiplace, 1980), leading to the remarkable conclusion that the molecular determinants of BK channel kinetics must be tonotopically distributed as well.

BK-dependent electrical tuning also is observed in hair cells of the avian basilar papilla (Fuchs et al., 1988; Fuchs and Evans, 1990 ) in addition to a gradient in the mechanical properties of the basilar membrane (Gummer et al., 1987). BK channels in chick are encoded by the slo gene (Jiang et al., 1997) originally identified in Drosophila (Atkinson et al., 1991; Adelman et al., 1992) and subsequently in mammals (Butler et al., 1993; Tseng-Crank et al., 1994). The presence of multiple splice sites in slo mRNA makes alternative splicing a candidate mechanism for generating

\footnotetext{
Received Aug. 25, 1999; revised Dec. 10, 1999; accepted Dec. 13, 1999.

This work was supported by Grant DC00276 from the National Institute on Deafness and Other Communication Disorders. We thank Dr. G.-J. Jiang for the cloning and construction of $c$ Slo splice variants, Dr. Corinna Sonderegger for the quail $\beta$ subunit, and Dr. R. Swanson for the bovine $\beta$ subunit. We also thank Drs. M. Zidanic and J. B. Yang for PCR identification of alternate exons in chick hair cells.

Correspondence should be addressed to Paul Fuchs, Center for Hearing Science, Traylor Research Building, Room 521, Johns Hopkins University School of Medicine, Baltimore, MD 21205. E-mail: pfuchs@bme.jhu.edu.

Copyright (c) 2000 Society for Neuroscience $0270-6474 / 00 / 201675-10 \$ 15.00 / 0$
}

occurring splice variant containing three additional exons deactivated 20 -fold more slowly when combined with $\beta$. Deactivation kinetics were used to predict tuning frequencies and thus tonotopic location if hair cells were endowed with each of the expressed channels. All $\beta$-containing channels were predicted to lie within the apical (low-frequency) $30 \%$ of the epithelium, consistent with previous in situ hybridization studies. Individual slo- $\alpha$ exons would be found anywhere within the apical $70 \%$, depending on the presence of $\beta$, and other alternative exons. Alternative splicing of the slo- $\alpha$ channel message provides intrinsic variability in gating kinetics that is expanded to a wider range of tuning by modulation with $\beta$ subunits.

Key words: calcium-activated potassium channel; electrical tuning; $\beta$ subunits; alternative splicing; cochlea; hair cell; avian; chick

the functional heterogeneity of hair cell BK channels (Navaratnam et al., 1997; Rosenblatt et al., 1997; Jones et al., 1998). However, initial expression studies of chick hair cell slo splice variants in human embryonic kidney 293 (HEK293) cells or oocytes revealed no kinetic differences (Jiang et al., 1997; Michael et al., 1997; Rosenblatt et al., 1997). Furthermore, the expressed slo channels required substantially higher levels of calcium for their activation (especially at negative membrane potentials) than do native hair cell BK channels (Art et al., 1995). Although higher calcium affinities might be found in other splice variants, these inconsistencies imply that native hair cell BK channels may contain other components that combine with and modify the slo- $\alpha$ gene product.

Studies of BK channels from smooth muscle have identified an accessory $\beta$ subunit whose co-expression confers increased voltage and calcium sensitivity onto the pore-forming slo- $\alpha$ subunit (McManus et al., 1995; Dworetzky et al., 1996; Meera et al., 1996; Saito et al., 1997). An avian homolog of the $\beta$ subunit was shown to be expressed in quail cochlear hair cells (Ramanathan et al., 1999). Co-expression of chick hair cell slo- $\alpha$ with quail $\beta$ subunits greatly increased open probability at negative membrane potentials, giving the expressed channels a calcium and voltage sensitivity close to that of native hair cell BK channels. In the present study, we examine $\beta$ modulation of several slo splice variants over a wide range of voltage and calcium concentrations. We estimate the tuning frequencies for eight varieties of $\mathrm{BK}$ channel and predict the corresponding position of each gene product along the tonotopically organized basilar papilla of the chick.

\section{MATERIALS AND METHODS}

Construction of clones and HEK transfection. $\alpha_{0}$ (cSlo1, GenBank number U23821) was cloned by homology screening of a chick cochlear cDNA 
library (Jiang et al., 1997). Chimeric splice variant clones were constructed by inserting "exon-present" RT-PCR products into the $\alpha_{0}$ cDNA by ligation of the restricted products. Final sequence of each chimeric construct was confirmed using primers upstream of the added exons. Plasmids for expression in the mammalian HEK293 cell line were created by packaging the full-length cDNA clone into pcDNA 3.1 (Invitrogen, Carlsbad, CA). Before recording, cells were propagated in DMEM (Life Technologies, Gaithersburg, MD) supplemented with $10 \%$ fetal bovine serum (Life Technologies). Cells were transfected using calcium phosphate precipitation. The mixture included green fluorescent protein (GFP) cDNA (pGreenLantern, Life Technologies) to label transfected cells. Recordings were made $24-48 \mathrm{hr}$ after transfection.

The quail $\beta$ subunit of the slo protein (GenBank accession number U67865) was a gift from C. Sonderegger and K. Bister (University of Innsbruck, Austria). This was subcloned into pCDNA 3.1 for expression in mammalian cells. The bovine $\beta$ subunit was obtained from R. Swanson (Merck, Sharp \& Dohme, West Point, PA) (Q28067) (Knaus et al., 1994) and cloned in frame into the pGreenLantern-1 vector to form a chimera with the gene for GFP. The GFP signal was then used to identify cells transfected with the bovine $\beta$ subunit.

RT-PCR using basilar papilla and hair cells. The quail inner ear was harvested to perform RT-PCR experiments to confirm the presence of the $\beta$ subunit in the cochlea. Quail hatchlings were killed, and their basilar papillae were dissected out and immediately frozen in liquid nitrogen. Purification of RNA involved homogenization of each cochlea in $50 \mu \mathrm{l}$ of Trizol (Life Technologies). After a brief incubation, $25 \mu \mathrm{l}$ of chloroform was added and mixed thoroughly. The emulsion was then centrifuged at $>13,000 \times g$ to separate the aqueous and organic phases. The RNA contained in the aqueous phase was transferred to a clean Eppendorf tube, and $25 \mu \mathrm{l}$ of isopropanol was added to it. The mixture was again centrifuged at $>13,000 \times g$ to precipitate a glassy RNA pellet. Aqueous isopropanol mixture was decanted, and the pellet was washed using chilled $75 \%$ ethanol. The RNA pellet was dried and dissolved in 20 $\mu \mathrm{l}$ of RNase free water. RT-PCR experiments were performed using a one-step kit from Life Technologies. Primers spanning the $5^{\prime}$ (agctccgctgcctcacattggg) and $3^{\prime}$-(agtgcctttgttctgtcttggc) untranslated regions of the cDNA were used to amplify slo- $\beta$ from quail cochlear tissue.

slo- $\alpha$ splice variants were identified initially by RT-PCR of chick brain RNA with primers that spanned $\sim 1000$ base pairs near the $C$ terminus of the $\alpha_{0}$ sequence (referred to originally as cslo1) (Jiang et al., 1997). When the PCR product was run on gels, two bands were identified, one of which was larger than that predicted from the $\alpha_{0}$ sequence. When isolated, subcloned, and sequenced, this brain PCR product was found to contain a 12 nucleotide insert at site 3 (encoding amino acids SRKR), and an 84 nucleotide insert at site 6 (encoding the 28 amino acid insert AKP... TEL). Some of the clones also contained a nine nucleotide insert at splice site 4 (encoding amino acids IYF). PCR of a chick's cochlear cDNA library, and RT-PCR from cochlear tissue, was next conducted using primers that encompassed the sequences of the site 3 and site 6 inserts (5'-3'-cagaagccgaaagcgtat, $3^{\prime}-5^{\prime}$-aaggcagaagtttgccaggc). This reaction resulted in two bands that differed by $\sim 200$ base pairs. When sequenced the larger product was found to contain the site 4, 61 amino acid exon (IYS. . . RAF, GenBank sequence AF076268).

A nested PCR strategy was used to identify these same transcripts in single hair cells, as described previously (Lustig et al., 1999). Individual hair cells were microdissected, identified under a compound inverted microscope (Nikon Diaphot), and aspirated into a suction pipette $(\sim 3$ $\mu \mathrm{M}$ tip opening). Each hair cell was ejected into a microfuge tube containing $10 \mu \mathrm{l}$ of RNase-free distilled water and RNase inhibitor and immediately frozen on dry ice. After reverse transcription with a specific primer, an initial round of PCR was performed using primers to generate a product that spanned the carboxy half of the transcript. A second round of PCR was then performed using the exon-specific primers listed above. Two bands were identified on gels. The larger of these was sequenced and shown to correspond to the $\alpha_{61}$ splice variant.

Electrophysiological recordings and analysis. Patch-clamp recordings were performed on inside-out patches with symmetric potassium ion concentrations of $146 \mathrm{~mm}$. All solutions were buffered with $10 \mathrm{~mm}$ HEPES and contained $0.5 \mu \mathrm{M} \mathrm{MgCl} \mathrm{M}_{2}$. Depending on the required free calcium concentration, $2 \mathrm{mM}$ of an appropriate calcium chelator was titrated with $\mathrm{CaCl}_{2}$. The free calcium concentrations were estimated using Henderson-Hasselbach equations, and the appropriate $K_{\mathrm{D}}$ values for the chelating compounds were obtained from Bers et al. (1994). The free concentrations of calcium were confirmed using a calcium electrode (Microelectrodes, Inc., Bedford, NH). Standard calcium solutions for cali- bration of the electrodes were purchased from World Precision Instruments (Sarasota, FL). The $200 \mathrm{~nm}$ calcium solution was buffered with $2 \mathrm{~mm}$ EGTA; 1, 2, and $5 \mu \mathrm{M}$ calcium solutions were buffered with $2 \mathrm{~mm}$ $\mathrm{Br}_{2}$ BAPTA (Molecular Probes, Portland, OR), and 20 and $50 \mu \mathrm{M}$ calcium solutions were buffered with $2 \mathrm{~mm}$ nitrilo triacetic acid. Unless noted otherwise, all chemicals were obtained from Sigma (St. Louis, MO).

Glass electrodes for patch-clamp recording were pulled from borosilicate glass capillaries (Drummond Scientific Company, Broomall, PA). Electrodes with resistance between 2.5 and $5 \mathrm{M} \Omega$ were used. Data were collected using an Axopatch 200A amplifier (Axon Instruments, Foster City, CA) and digitized through an ITC 16 interface (Instrutech Corporation, Great Neck, NY) using Igor Pro 3.1 (Wavemetrics, Lake Oswego, OR) on a Macintosh 8100. Custom macros were written in Igor Pro to analyze the currents and fit the data to user-defined equations. Least square fits to activation and deactivation kinetics were performed in KaleidaGraph (Synergy Software).

\section{RESULTS}

\section{slo channel subunits in the avian cochlea}

The pore-forming $\alpha$ subunit of BK channels in hair cells is encoded by the slo mRNA, which is subject to alternative splicing (Jiang et al., 1997; Navaratnam et al., 1997; Rosenblatt et al., 1997; Jones et al., 1998, 1999; Ramanathan et al., 1999). We have used a PCR-based cloning strategy to identify and sequence alternative exons found at three splice sites in the hair cell slo cDNA. Initial RT-PCR studies were conducted using mRNA isolated from chick brain to identify candidate alternative exons. PCR using a chick's cochlear cDNA library, as well as reversetranscribed cDNA from individual hair cells, confirmed the presence of a number of alternative exons in hair cell slo cDNA. A 4 amino acid insert at splice site 3, a 61 amino acid insert at site 4, and a 28 amino acid exon at site 6 were used in the present study (Fig. 1). Splice sites are numbered according to Fettiplace and Fuchs (1999).

Figure 1 shows a schematic of the slo gene with position, relative size, and amino acid sequence of each alternative exon. PCR products containing individual exons or exon combinations were treated with specific endonucleases and ligated into a fulllength cDNA from the cochlear library (Jiang et al., 1997) to produce the set of chimeric $\alpha$ subunits shown in the table in Figure 1. Thus a total of four $\alpha$ subunit splice variants have been examined, and they are named for the "extra" exon(s) that they include. $\alpha_{0}$ corresponds to "cslo1" (GenBank U23821), which was isolated as a single contiguous cDNA and so corresponds to a naturally occurring channel. In addition, a partial cDNA encoding the three exon combination $\alpha_{4-61-28}$ was found in brain, in cochlea, and in single hair cells by RT-PCR, whereas an RT-PCR product corresponding to the $\alpha_{4}$ exon combination was sequenced from brain. It is not known whether a channel like $\alpha_{61}$ occurs naturally in hair cells, because this insert was obtained by RTPCR using primers specific to the site 3, 4 amino acid and site 6, 28 amino acid inserts (see Materials and Methods).

Endogenous BK channels may be composed of a combination of pore-forming $\alpha$ and accessory $\beta$ subunits. A $\beta$ subunit of the BK channel was first identified and cloned from bovine smooth muscle (McManus et al., 1995). A putative quail homolog of $\beta$ was identified and isolated by differential screening of quail fibroblasts after oncogenic transformation (Oberst et al., 1997). A chick ortholog of the quail $\beta$ was also described [C. Sonderegger (né Oberst), PhD thesis, University of Innsbruck, Austria]. RT-PCR was used to determine whether this fibroblast gene product also was expressed in the quail basilar papilla (cochlea) (Fig. 2A). RT-PCR from microdissected basilar papilla using $\beta$-specific primers yielded an 800 bp product that when sequenced proved 
(Transmembrane domains)

So S1----.-.-.-.---S6
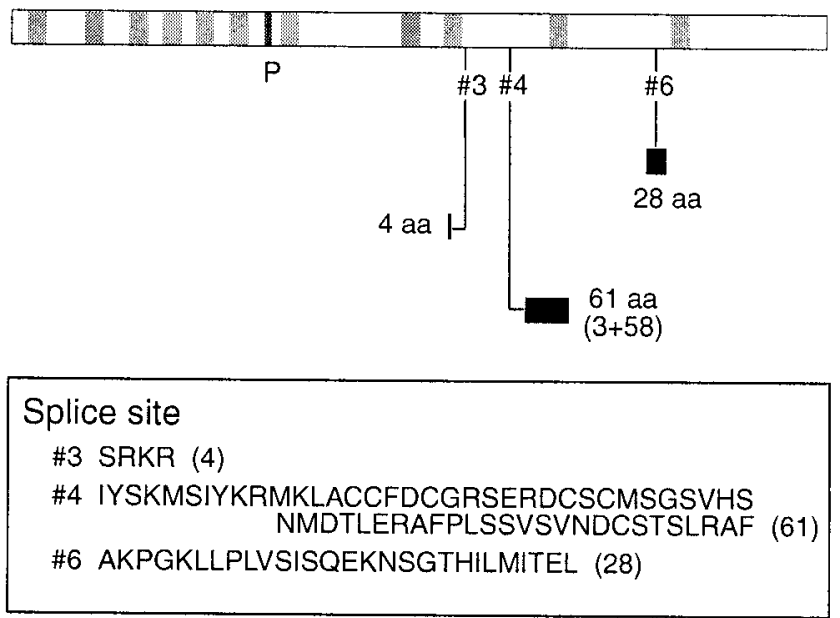

\begin{tabular}{|c|c|c|c|}
\hline Channel type & Site \#3 & Site \#4 & Site \#6 \\
\hline$\alpha_{0}$ & - & - & - \\
\hline$\alpha_{61}$ & - & + & - \\
\hline$\alpha_{4}$ & + & - & - \\
\hline$\alpha_{4-61-28}$ & + & + & + \\
\hline
\end{tabular}

Figure 1. slo- $\alpha$ splice variants. A schematic layout of the slo- $\alpha$ gene is shown at top. The shaded areas are hydrophobic regions of the protein. The extended C-terminal region (after S6) of the protein houses the calcium binding site and several splice sites (\#3-\#6). We have examined channels with a four amino acid insert at site \#3 $\left(\alpha_{4}\right)$, a 61 amino acid insert at site \#4 $\left(\alpha_{61}\right)$, and a channel with both of these plus a 28 amino acid exon at site \#6 $\left(\alpha_{4-61-28}\right)$, in addition to the full-length $\left(\alpha_{0}\right)$ cloned initially. The amino acid sequences of the different alternative exons are shown in the middle panel. The bottom panel shows the channel types and the exon combinations present in each channel type. Splice sites are numbered according to Fettiplace and Fuchs (1999).

nearly identical to quail $\beta$ (4 of 300 bases differed). This PCR product was then subcloned into a mammalian expression vector for the transfection studies with slo- $\alpha$ cDNAs described below.

Avian (quail) $\beta$ was initially identified on the basis of a Blast search that showed sequence similarity to only one entity in GenBank: the mammalian slo- $\beta$ gene (Oberst et al., 1997). However, the level of identity is not very high; only $40 \%$ of the amino acids are shared in quail and bovine $\beta$ sequences (Fig. $2 B$ ). On the other hand, hydrophobicity analysis suggests a similar topology (Oberst et al., 1997), with two putative transmembrane segments (Wallner et al., 1996) separated by an extracellular loop, implying conserved secondary and tertiary structure of the mammalian and avian proteins and perhaps shared function. To test this suggestion further, bovine and quail $\beta$ subunits were compared for their functional effects when co-expressed with chick slo- $\alpha$ channels. Co-expression with either $\beta$ subunit resulted in BK channels with more negative voltage activation ranges and slowed deactivation kinetics (Fig. 2C). However, the mammalian $\beta$ subunit produced significantly larger effects. The average shifts in the voltage of half-activation $\left(\Delta V_{1 / 2}\right)$ in $5 \mu \mathrm{M}$ calcium produced
A

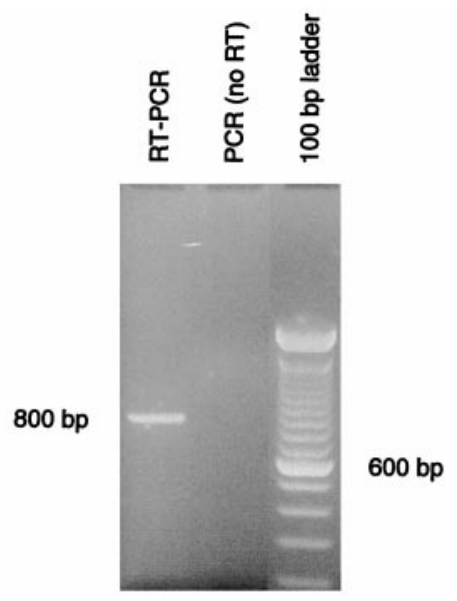

B
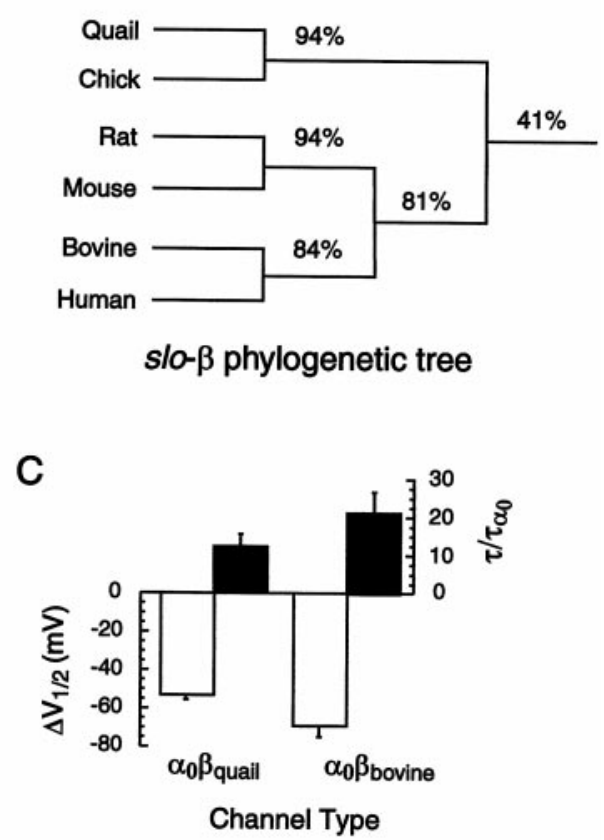

Figure 2. The $\beta$ subunit in bird cochlea. $A$, Total RNA was extracted from quail cochlear tissue as described in Materials and Methods and was screened for the presence of slo- $\beta$ RNA using a single-step RT-PCR assay. Lane 1 is a single round RT-PCR product from quail cochlear tissue; lane 2 is the control experiment, which lacked reverse transcriptase enzyme. The band in lane 1 corresponding to $\sim 800 \mathrm{bp}$ is the expected size of the slo- $\beta$ product between the two primers. $B$, The phylogenetic tree for $\beta$ subunits of BK channels shows that the avian isoforms are nearly identical to each other and that mammalian isoforms have significant homology. However, mammalian and avian $\beta$ subunits shared only $41 \%$ of the amino acids. $C$, Bovine $\beta$ subunits had an effect that was qualitatively like that of quail $\beta$ subunits on $\alpha_{0}$. The bar plot shows the half-activation voltage at $5 \mu \mathrm{M} \mathrm{Ca}^{2+}$ and the time constant of deactivation of tails at $-100 \mathrm{mV}$ membrane potential at $5 \mu \mathrm{M} \mathrm{Ca}^{2+}$ for $\alpha_{0}$ co-expressed independently with quail or bovine $\beta$ subunits. Open bars show the shift in $V_{1 / 2}$ when comparing $\alpha_{0}$ alone with $\alpha_{0} \beta$. Filled bars show the change in the deactivation time constant of $\alpha_{0} \beta$ channels as a ratio with that of $\alpha_{0}$ alone. The change in steady-state and kinetic parameters attributable to $\beta$ addition was larger with slo- $\beta_{\text {bovine }}$ than with slo- $\beta_{\text {quail }}$.

by quail and bovine $\beta$ were 55 and $70 \mathrm{mV}$, respectively. The time constant of deactivation was increased 20 -fold by bovine $\beta$, compared with only a 12 -fold increase with quail $\beta$. The methods used to derive these values will be described in the following sections. 


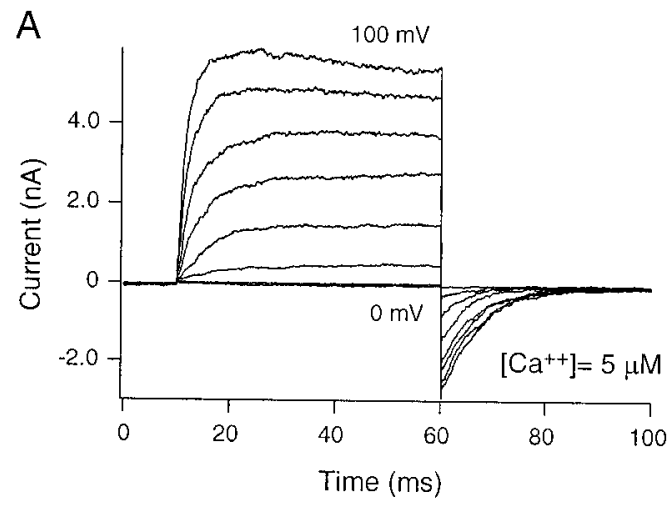

B

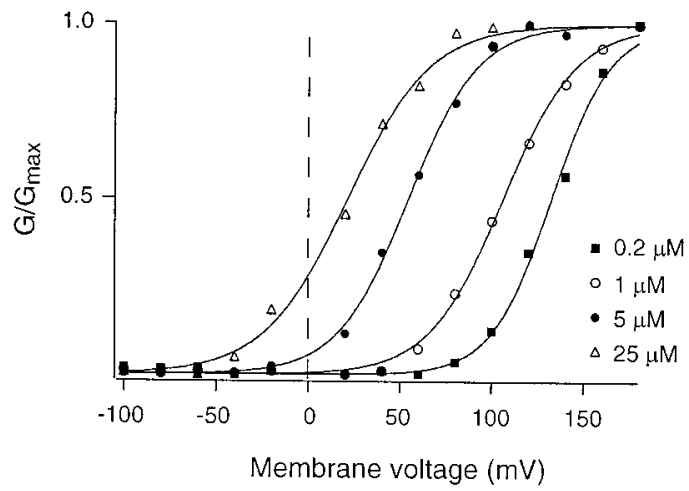

Figure 3. Gating of $\alpha_{0}$ channels. Inside-out patches from HEK293 cells containing BK channels formed by $\alpha$-subunits alone $\left(\alpha_{0}\right)$ were exposed to different concentrations of calcium. Voltage protocols used to test the steady-state open probability were designed to span the activation range of the channel for each calcium concentration. $A$, Currents from one inside-out patch exposed to $5 \mu \mathrm{M} \mathrm{Ca}^{2+}$. The activation voltage ranges from 0 to $+100 \mathrm{mV}$ (in steps of $10 \mathrm{mV}$ ), and deactivating tail currents were measured at $-50 \mathrm{mV}$. Instantaneous currents at the onset of the tail voltage were used as an estimate of the conductance of the channels in the patch. $B$, Four different calcium concentrations $(0.2,1,5$, and $25 \mu \mathrm{M})$ were tested. $G / G_{\max }$ was fit with a Boltzmann distribution between closed and open states (Eq. 1). The leftward shift in $G-V$ relationships with increasing concentrations of calcium on the "cytoplasmic" side of the channels illustrates the calcium and voltage dependence of the BK channel.

\section{$\boldsymbol{\beta}$ modulation of BK voltage dependence}

BK potassium channel gating properties were studied under voltage clamp while inside-out membrane patches from HEK 293 cells were exposed to an array of different calcium concentrations. Each patch contained tens to hundreds of channels. The plasmid coding for the $\beta$ subunit was transfected in excess (twofold DNA by weight), thereby maximizing $\beta$ interaction with the poreforming $\alpha$ subunits. The following experiments examine the nature of the effect of the $\beta$ subunit on the backbone (no added exons) BK channel $\left(\alpha_{0}\right)$. First, the steady-state properties were examined to determine open probabilities as a function of calcium concentration and membrane voltage, and then the kinetics of activation and deactivation were compared.

Figure $3 A$ illustrates the growth in current magnitude through $\alpha_{0}$ channels during a family of depolarizing voltage commands. The steady-state open probability of the channels (plotted as a function of voltage) obeyed a Boltzmann distribution between open and closed states (Fig. $3 B$ ). $\alpha_{0}$ activated at more negative membrane potentials as the concentration of "cytoplasmic" calcium was increased. On co-expression, $\alpha_{0} \beta$ activated at more
A

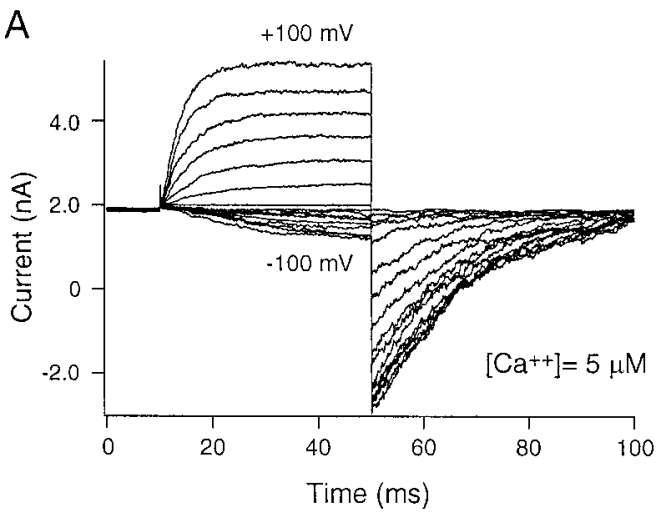

B

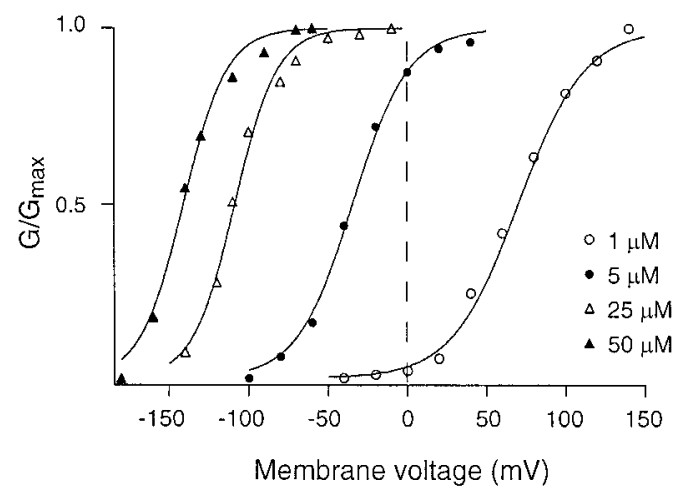

Figure 4. Gating of $\alpha_{0} \beta$ channels. Patches containing BK channels formed by co-expressing both $\alpha_{0}$ and $\beta$ (henceforth referred to as $\alpha_{0} \beta$ ) were subject to voltage protocols as in Figure 3. $A$, Currents across the patch exposed to $5 \mu \mathrm{M} \mathrm{Ca}^{2+}$ for activation voltages ranging from -100 to $+100 \mathrm{mV}$ (steps of $10 \mathrm{mV}$ ). Tail currents were measured at $-100 \mathrm{mV}$. B, $G-V$ relationships obtained at four different calcium concentrations (1, 5, 25 , and $50 \mu \mathrm{M}$ ) were fit with Boltzmann functions described in Equation 1. Notice that $\alpha_{0} \beta$ activates at more negative voltages than does $\alpha$ alone, and increasing the calcium concentration causes a greater leftward shift in the activation curve for $\alpha_{0} \beta$.

negative membrane potentials than $\operatorname{did} \alpha_{0}$ when exposed to the same concentration of calcium (Fig. 4). Thus $G(V)$ curves for $\alpha_{0} \beta$ channels (Fig. 4B) are left shifted compared with those for $\alpha$ alone (Fig. 3B).

Half-activation voltage $\left(V_{1 / 2}\right)$ at each calcium concentration was calculated by fitting the steady-state fractional activation curve with Boltzmann functions:

$$
\frac{G}{G_{\max }}=\frac{1}{1+\exp \left(-\left(V-V_{1 / 2}\right) q F / R T\right)}
$$

where $V_{1 / 2}$ is the voltage at which half the channels are open, and $q$ is the amount of gating charge. $F, R$, and $T$ are Faraday's constant, the universal gas constant, and the absolute temperature, respectively. The effect of co-expressing $\beta$ subunits was to shift activation to more negative voltages (Fig. $5 A$ ). Gating charge $(q)$ in these fits varied between $1.4 \mathrm{e}$ and $2.0 \mathrm{e}$, but no consistent difference in gating charge between $\alpha_{0}$ and $\alpha_{0} \beta$ was found.

\section{Comparison of calcium sensitivities}

The goal here is to examine the calcium and voltage-dependent gating properties of $\alpha_{0}$ and $\alpha_{0} \beta$ using a simple two-state model in an effort to extract parameters that can be used to compare the different channel types. The model assumes that voltage- 
A

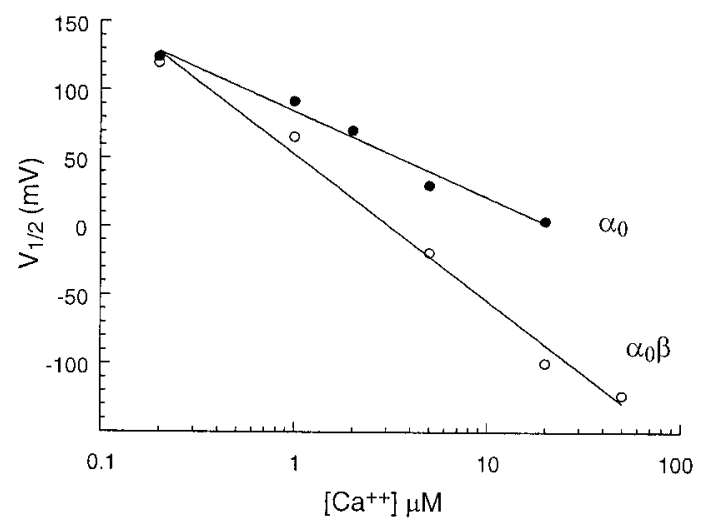

B

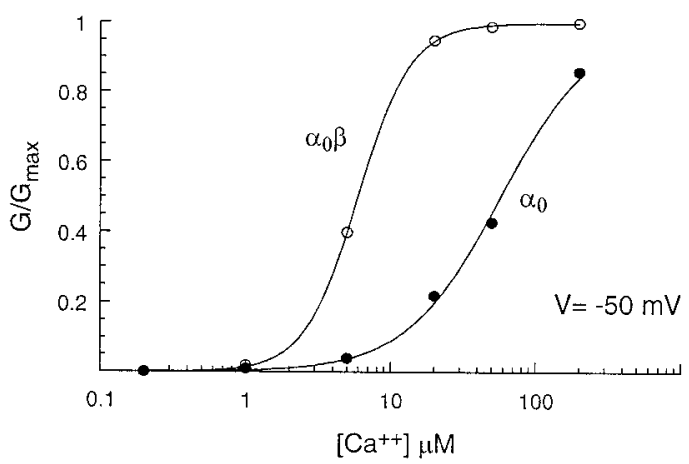

C

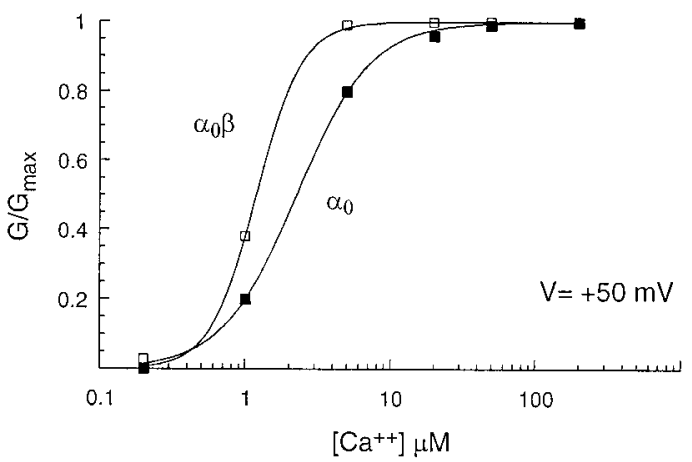

Figure 5. The effect of calcium on voltage gating. Average $(n>10)$ half-activation voltages $\left(V_{1 / 2}\right)$ were estimated from Boltzmann fits to $G-V$ relationships for different cytoplasmic calcium concentrations (Figs. 3, 4). Standard error bars are comparable to the size of the symbols used. The line is a least squares fit to $\left(V_{1 / 2}=\mathrm{A} * \log \left[\mathrm{Ca}^{2+}\right]+\mathrm{B}\right) \cdot \alpha_{0} \beta$ showed a higher steady-state affinity and a greater sensitivity to calcium than $\operatorname{did} \alpha_{0}$. $B, G / G_{\max }$ (as measured in Figs. 3, 4) for $\alpha_{0}$ and $\alpha_{0} \beta$ at $-50 \mathrm{mV}$ is plotted as a function of the calcium concentration. The results are from a single experiment in which all calcium conditions were used. Six different concentrations of calcium were used $(200,1,5,25,50$, and $200 \mu \mathrm{M})$. The points were fit with a Hill equation (Eq. 5) to obtain the concentration of calcium necessary to open half of the channels $\left(K_{\mathrm{D}}\right)$ and the Hill coefficient $(n)$. $C$, Same analysis at $+50 \mathrm{mV}$. The effect of $\beta$ addition was greater at $-50 \mathrm{mV}$ than at $+50 \mathrm{mV}$.

dependent binding of calcium as a first order process leads to channel opening:

$$
\mathrm{C} \stackrel{k_{1}\left[\mathrm{Ca}^{2+}\right] \exp (2 \delta F V / R T)}{\rightleftharpoons} \mathrm{O} .
$$

Table 1. Calcium binding

\begin{tabular}{lcccc} 
& \multicolumn{3}{l}{ Channel type } & $\alpha_{0} \beta$ \\
\cline { 2 - 5 } & $\alpha_{0}$ & & \\
\hline Membrane voltage & $+50 \mathrm{mV}$ & $-50 \mathrm{mV}$ & $+50 \mathrm{mV}$ & $-50 \mathrm{mV}$ \\
Hill coefficient $(n)$ & 1.5 & 1.4 & 2.9 & 2.4 \\
Calcium affinity $\left(K_{\mathrm{D}}\right)$ & $2.05 \mu \mathrm{M}$ & $57.2 \mu \mathrm{M}$ & $1.18 \mu \mathrm{M}$ & $5.9 \mu \mathrm{M}$ \\
\hline
\end{tabular}

$k_{1}$ and $k_{-1}$ are the forward and reverse rates for the binding of calcium at $0 \mathrm{mV}$, and $\delta$ is an expression for the energy consumed in the binding process. Using Scheme 2, the activation of the channel may be defined as a function of calcium concentration:

$$
\frac{G}{G_{\max }}=\frac{1}{1+\frac{K_{\mathrm{D}}(0) \exp (-2 \delta F V / R T)}{\left[\mathrm{Ca}^{2+}\right]}} .
$$

The steady-state calcium affinity $K_{\mathrm{D}}(0)$ is the ratio of $k_{-1}$ to $k_{1}$ (the concentration of calcium needed to open half of the channels at a membrane voltage of $0 \mathrm{mV}$ ). Equation 3 can be rearranged to represent the half-activation voltage $\left(V_{1 / 2}\right)$ as a logarithmic function of calcium concentration (Eq. 4) (Cui et al., 1997):

$$
V_{1 / 2}=-\frac{2.303 R T}{2 \delta F} \log \left(\left[\mathrm{Ca}^{2+}\right]\right)+\frac{2.303 R T}{2 \delta F} \log \left[K_{\mathrm{D}}(0)\right] .
$$

$V_{1 / 2}$ is plotted as a function of calcium concentration for $\alpha_{0}$ and $\alpha_{0} \beta$ in Figure $5 A$. The coefficients of the straight line fit in Figure $5 A$ were compared with the parameters in Equation 4 to determine the values of $K_{\mathrm{D}}(0)$ and $\delta$ for each type of channel. Addition of the $\beta$ subunit lowered the concentration of calcium needed to open half of the channels at $0 \mathrm{mV}\left[K_{\mathrm{D}}(0)\right]$. In the absence of $\beta$ subunit, the $K_{\mathrm{D}}(0)$ was $24 \mu \mathrm{M}$, and the addition of the $\beta$ subunit reduced it to $3.3 \mu \mathrm{M}$. $\delta$ was simultaneously reduced from 0.5 to 0.3 by $\beta$ addition. The difference between the two species of channels can be explained by a mechanism whereby $\beta$ increases the apparent calcium sensitivity of $\alpha_{0}$.

Fractional activation $\left(G / G_{\max }\right)$ as a function of calcium concentration was fit with Hill relations to determine the calcium dependence of steady-state activation of both channels (Fig. $5 B, C)$. Near the hair cell resting membrane potential of $-50 \mathrm{mV}$, the half-activating calcium concentration $\left(K_{\mathrm{D}}\right)$ for $\alpha_{0}$ was $57.2 \mu \mathrm{M}$. In contrast, $\alpha_{0} \beta$ was half-activated by $5.9 \mu \mathrm{M}$ calcium at $-50 \mathrm{mV}$ (Fig. $5 B$ ). At $+50 \mathrm{mV}, \alpha_{0}$ was half-activated with $2.05 \mu \mathrm{M}$ calcium, and $\alpha_{0} \beta$ was half-activated with $1.18 \mu \mathrm{M}$ calcium (Fig. $5 C$ ). The $\beta$ subunit enhanced the calcium sensitivity of the BK channel and that effect was more pronounced at negative membrane potentials:

$$
\frac{G}{G_{\max }}=\frac{1}{1+\left(\frac{K_{\mathrm{D}}}{\left[\mathrm{Ca}^{2+}\right]}\right)^{\mathrm{n}}} .
$$

$K_{\mathrm{D}}$ is the calcium concentration needed to open half of the channels, and $n$ is the Hill coefficient. The parameters of these fits are listed in Table 1. The stoichiometry of calcium binding to the channels is derived from the Hill Equation 5. The Hill coefficient of $\alpha_{0} \beta$ channels at $-50 \mathrm{mV}$ was 2.4 , whereas that of $\alpha_{0}$ was 1.4. Table 1 shows values from single experiments in which a sufficient range of calcium concentrations could be tested. However, the 
A

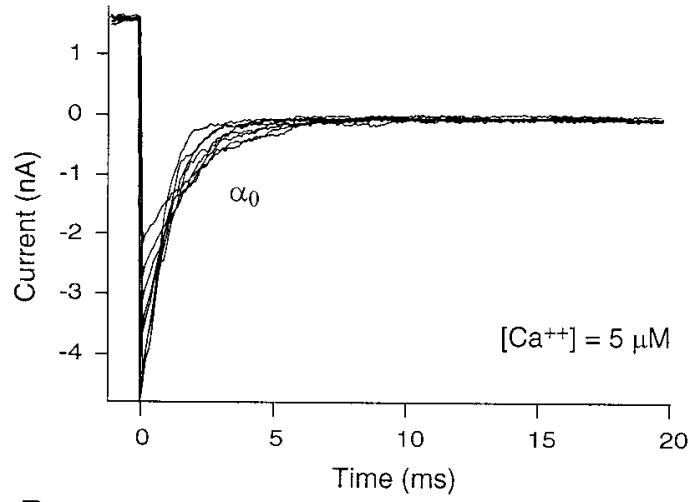

B

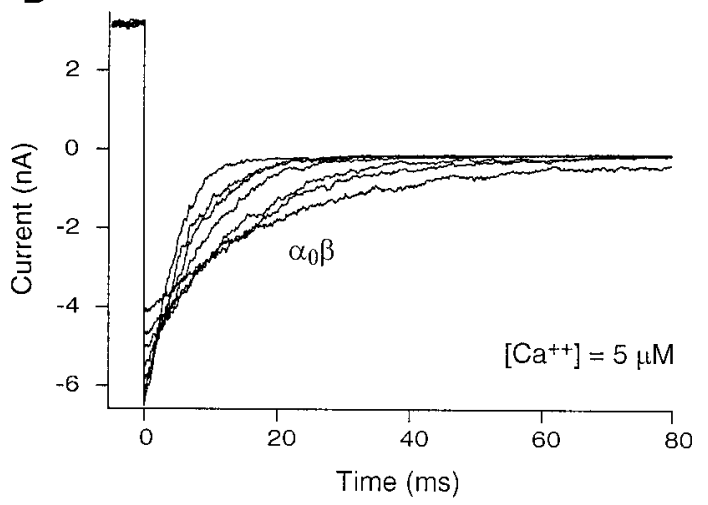

Figure 6. Effect of $\beta$ subunit on deactivation time constant. $A$, Currents were measured from a macro patch containing $\alpha_{0}$. The channels were activated with a brief depolarization to $+120 \mathrm{mV}$ and then allowed to relax at a family of voltages ranging from -50 to $-120 \mathrm{mV}$ in steps of 10 $\mathrm{mV}$. The panel shows decaying "tail" currents at a calcium concentration of $5 \mu \mathrm{M}$. The time constant of deactivation was determined by fitting single exponential functions of the form $I=I_{0} \exp (-t / \tau)$, where $I_{0}$ is the instantaneous current at the beginning of the deactivation pulse and $\tau$ is the time constant. $B$, Patches containing $\alpha_{0} \beta$ were stepped to $+60 \mathrm{mV}$ and thereafter from -80 to $-150 \mathrm{mV}$. Notice the substantial slowing of the tail currents (changed scale bar on $\mathrm{x}$-axis) on $\beta$ addition. Tail currents were slowed $>10$-fold by the addition of $\beta$ subunits.

generality of this conclusion is supported by the data in Figure $5 A$ averaged from $>10$ experiments. The slope of the relation between $V_{1 / 2}$ and calcium concentration differs significantly between the two channel types, consistent with a steeper dose-response relation to calcium for the $\alpha_{0} \beta$ channel.

\section{Effects of $\boldsymbol{\beta}$ on kinetics}

BK channels are activated by voltage and calcium transients (Marrion and Tavalin, 1998). This makes it important to study the kinetic behavior of the channel as well as the steady-state activation and open probability. More importantly, hair cell tuning frequencies have an intimate dependence on the deactivation kinetics of BK channels expressed in each hair cell (Art et al., 1995).

To study deactivation kinetics, "tail" currents were recorded at various relaxation voltages for $\alpha_{0}$ and $\alpha_{0} \beta$ (Fig. 6, $A$ and $B$, respectively). Under steady-state conditions, $\alpha_{0} \beta$ binds calcium more tightly than $\alpha_{0}$, as evidenced by higher $K_{\mathrm{D}}$ values (Table 1 ). Because calcium binding tends to keep the channels open (from the two-state model in Eq. 2), we would predict that the greater calcium sensitivity of $\alpha_{0} \beta$ produces a longer dwell time in the open state, and so it would deactivate more slowly. Experiments
A

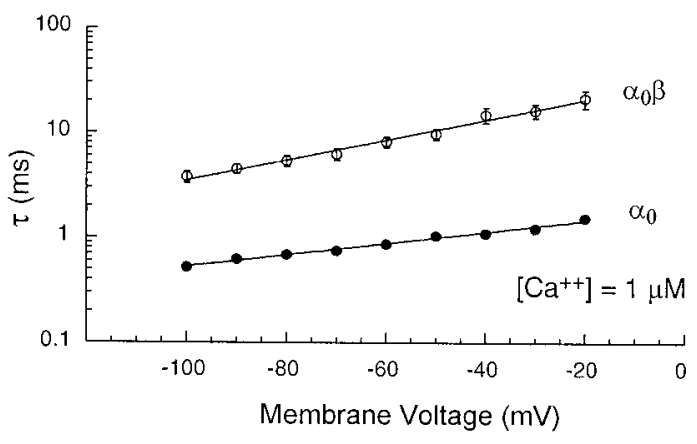

B

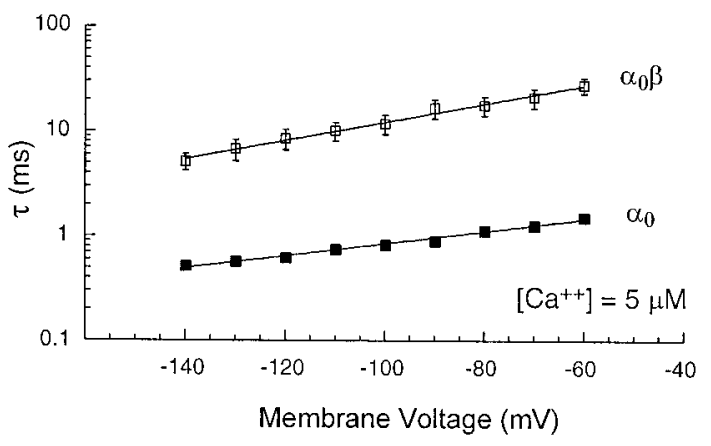

Figure 7. Deactivation time constants at different membrane potentials in $1 \mu \mathrm{M}(a)$ and $5 \mu \mathrm{M}(b)$ calcium. Time constants were calculated from single exponential fits to tail currents as in Figure 8. The data points were fit with an exponential function given by $\tau=\tau_{0} \exp \left(q_{\mathrm{b} F V} / R T\right)$, where $\tau_{0}$ is the time constant at $0 \mathrm{mV}$ and $q_{\mathrm{b}}$ is the gating charge associated with the dependence of deactivation on membrane voltage $\left[q_{\mathrm{b}}\right.$ values for $\alpha_{0}$ and $\alpha_{0} \beta$ were $0.54 \pm 0.08$ and $0.76 \pm 0.12$ for $1 \mu \mathrm{M}\left(\mathrm{Ca}^{2+}\right) ; 0.58 \pm 0.10$ and $0.80 \pm 0.14$ for $5 \mu \mathrm{M}\left(\mathrm{Ca}^{2+}\right)$, respectively]. $\beta$ co-expression causes slower deactivation at all membrane potentials and both calcium concentrations.

to determine the rate of relaxation under identical calcium concentrations showed that $\alpha_{0} \beta$ deactivated slowly when compared with $\alpha_{0}$ (Fig. 6). The addition of $\beta$ subunits prolonged the rate of relaxation $>10$-fold. The time constant of relaxation had an exponential dependence on the membrane voltage for both channels, indicating a concerted voltage-dependent rate of transition from the open to closed state. Higher concentrations of calcium prolonged the relaxation time constant (Fig. 7).

\section{$\boldsymbol{\beta}$ modulation of $\boldsymbol{\alpha}$ splice variants}

Thus far we have described some of the mechanistic features of channel diversity by examining the effects of combining $\beta$ subunits with just one $\alpha$ subtype $\left(\alpha_{0}\right)$. In an effort to extend our understanding, we undertook a similar analysis of three other $\alpha$ splice variants $\left(\alpha_{4}, \alpha_{61}\right.$, and $\left.\alpha_{4-61-28}\right)$ (Fig. 1) and their modulation by $\beta$ subunits. Steady-state conductance-voltage curves in varying calcium concentrations (as in Figs. 3 and 4) were constructed and used to determine the calcium affinity for each channel type $\left(K_{\mathrm{D}}\right.$, defined as the concentration of calcium that opens half of the channels at $0 \mathrm{mV}$ ). The $\alpha$ subunits expressed on their own exhibited substantial variation in calcium binding, ranging from nearly $40 \mu \mathrm{M}$ for $\alpha_{4}$ to $6 \mu \mathrm{M}$ for $\alpha_{61}$. After combination with $\beta$ subunits, all of the channels had significantly higher calcium affinities $(2-10 \mu \mathrm{M})$. The $\alpha_{0}$ and $\alpha_{4}$ channels had the weakest calcium affinity on their own and showed the largest changes after $\beta$ combination (Fig. $8 A$ ). Splice variants containing the 61 amino 
A

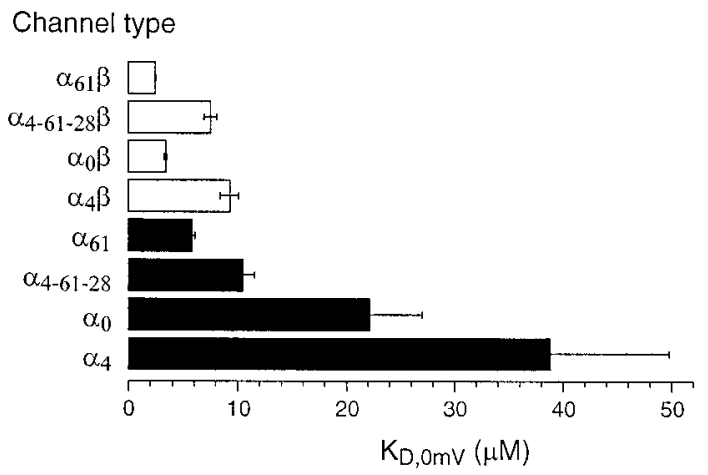

B

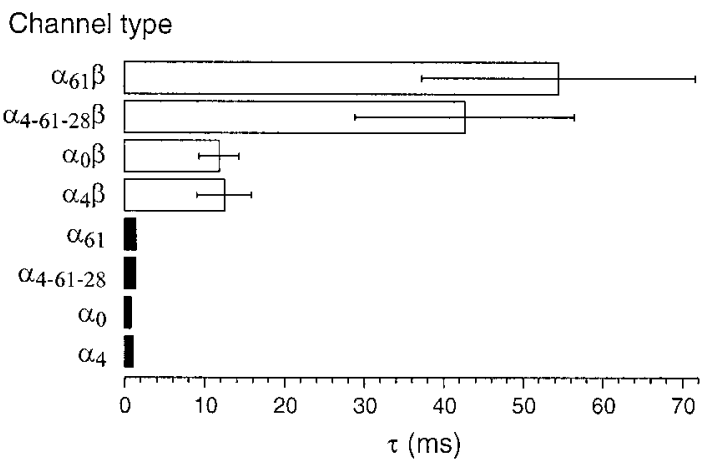

Figure 8. Calcium affinities at $0 \mathrm{mV}\left(K_{\mathrm{D}}\right)$ and deactivation time constants were compared for the eight channel types created by four splice variants expressed either with or without $\beta$ subunits. $A, K_{\mathrm{D}}$ values for $\alpha_{\mathrm{x}}$ (filled bars) and $\alpha_{\mathrm{x}} \beta$ (open bars) channels are shown, where $x$ denotes the different exons. $B$, Deactivation time constants measured at $-100 \mathrm{mV}$ membrane potential and $5 \mu \mathrm{M}$ "cytoplasmic" calcium for $\alpha_{\mathrm{x}}$ (filled bars) and $\alpha_{\mathrm{x}} \beta$ (open bars) channels. The net range in deactivation kinetics between the fastest $\alpha_{\mathrm{x}}$ and the slowest $\alpha_{\mathrm{x}} \beta$ is $>50$-fold. Error bars are standard errors from 5-10 experiments and are shown if they are larger than the width of the lines used in the bar plot.

acid exon had greater calcium affinity and were less affected by $\beta$ combination. $\alpha_{4-61-28}$ had a poorer calcium affinity than $\operatorname{did} \alpha_{61}$, as though it were an amalgam of the higher affinity $\alpha_{61}$ and lower affinity $\alpha_{4}$ calcium binding properties.

All four $\alpha$ splice variants had relatively rapid kinetics as homomeric channels. Time constants of deactivation at $-100 \mathrm{mV}$ and $5 \mu \mathrm{M}$ calcium ranged from $\sim 1$ to $2.5 \mathrm{msec}$ (Fig. $8 B$ ). Both $\alpha$ variants containing the 61 amino acid exon $\left(\alpha_{61}\right.$ and $\left.\alpha_{4,61,28}\right)$ were significantly slower than $\alpha_{0}$ and $\alpha_{4}$, which lacked this exon. Combination with $\beta$ subunits dramatically slowed all four channel types. However, the 61 amino acid exon-containing splice variants were more profoundly affected, showing a $>20$-fold increase in deactivation time constant. The splice variants $\alpha_{0}$ and $\alpha_{4}$ were slowed $\sim 10$-fold by combination with $\beta$ subunits.

\section{BK channel kinetic diversity and electrical tuning}

We have shown that eight functionally distinct BK channels can be generated by a combination of four alternatively spliced $\alpha$ subunits and one $\beta$ subunit. The deactivation rates span a 50-fold range between the fastest and slowest of these heterologously expressed channels, which approximates the variation in kinetics postulated to encompass electrical tuning over the chick's auditory frequency range (Wu and Fettiplace, 1996). Given the kinetic variability of the cloned channels, it would be useful to
A

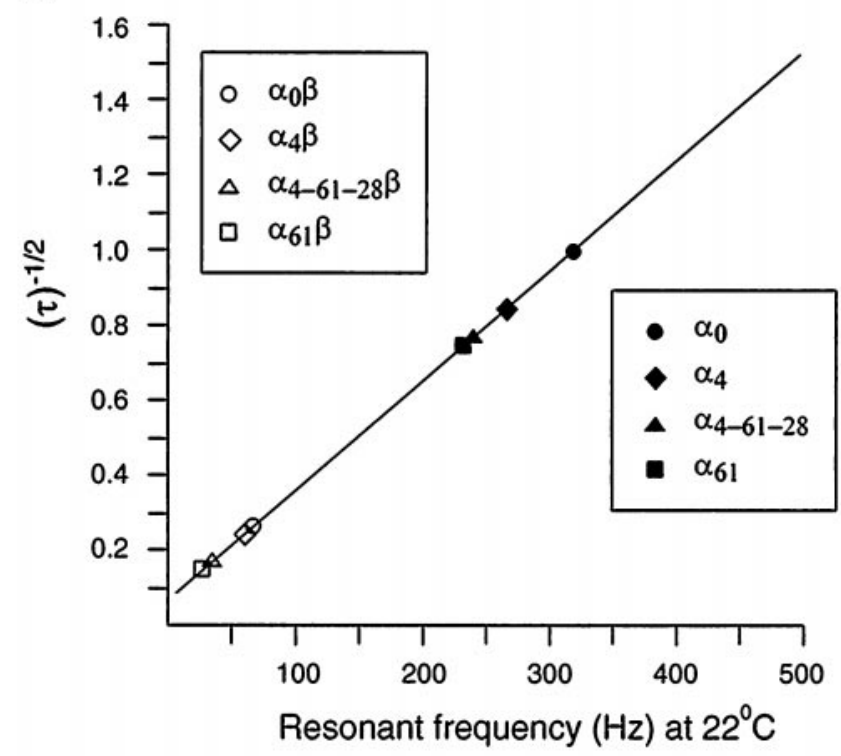

B
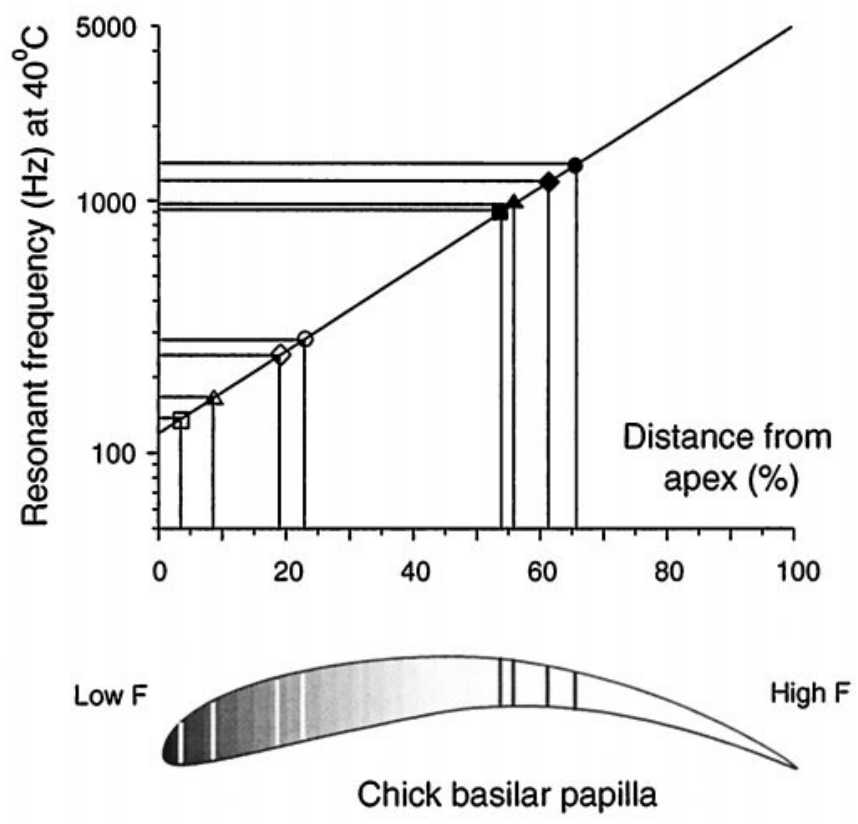

Distribution of $\beta$

Figure 9. Estimated tuning frequencies and cochlear position for each of eight $\mathrm{BK}$ channel variants. $A$, The straight line redrawn from $\mathrm{Wu}$ et al. (1995) shows the relation between ensemble average single BK channel deactivation time constants and resonant frequency in turtle hair cells. Deactivation time constants for eight channel variants (measured at $4 \mu \mathrm{M}$ calcium and $-50 \mathrm{mV}$ membrane potential) were overlaid to extrapolate a predicted frequency of tuning. $B$, Tuning frequency as a function of position along the cochlear axis [from Jones and Jones (1995)]. The resonant frequencies estimated from $A$ were corrected for the body temperature of the chick $\left(40^{\circ} \mathrm{C}\right)$ using a $Q_{10}$ value of 2 . The corrected frequencies were then mapped to a tonotopic position in the cochlea. The predicted positions are projected as lines across the schematic of the chick basilar papilla (below). The decreasing shade of gray from the cochlear apex is indicative of expression levels of $\beta$ along the tonotopic axis based on results from in situ hybridization (Ramanathan et al., 1999). 
estimate the tuning frequency that each would confer if expressed by a chick cochlear hair cell. Such an estimate can be obtained by comparing the properties of the cloned channels with those of BK channels in electrically tuned turtle hair cells, with appropriate corrections for the effects of temperature. The relationship between the time constant of deactivation and hair cell tuning frequency for turtle hair cells (Art and Fettiplace, 1987; Wu et al., 1995 ) is shown in Figure $9 A$ (straight line). The tuning frequency of turtle hair cells is inversely correlated with the square root of the time constant of whole-cell "tail" currents. The time constants of tail currents from cloned chick channels recorded under similar conditions are arrayed along that line to obtain an estimated tuning frequency. The $\beta$-combined channels (open symbols) all cluster at frequencies below $100 \mathrm{~Hz}$, whereas the " $\alpha$-only" channels (filled symbols) span a range of frequencies from 200 to $350 \mathrm{~Hz}$.

Because the experiments on cloned channels and turtle hair cells were conducted at room temperature, it is necessary to make a correction for the higher internal temperature of the chick $\left(40^{\circ} \mathrm{C}\right)$ to place these data into the context of the cochlear frequency map. The best frequency of cochlear afferents in pigeons was shown to vary with temperature with a $Q_{10}$ of 2 (Schermuly and Klinke, 1985), and voltage oscillations in hair cells isolated from the chick's cochlea showed a similar temperature dependence (Fuchs and Evans, 1990). Here we assume that electrical tuning produced by BK channels cloned from chick would show an equivalent temperature sensitivity, increasing the predicted tuning frequency for each channel type approximately fourfold. Finally, those temperature-corrected tuning frequencies were placed onto a cochlear frequency map based on the mapping of single cochlear afferents (Manley et al., 1987; Chen et al., 1994; Jones and Jones, 1995) (Fig. 9B). At $40^{\circ} \mathrm{C}$, the predicted tuning frequencies range from 105 to $1250 \mathrm{~Hz}$, and cochlear locations fall from the apical-most $5 \%$ to a position nearly $70 \%$ of the distance toward the base.

\section{Predicted expression patterns}

From these considerations a number of predictions can be made about the expression patterns of the gene products contributing to the hair cell BK channels. The effect of combination with the $\beta$ subunit is to slow BK channel gating kinetics, consistent with low-frequency tuning. Thus higher levels of $\beta$ expression ought to be found in hair cells from the cochlear apex, as indeed has been observed using in situ hybridization (Ramanathan et al., 1999). A hypothetical expression gradient for $\beta$ subunits based on the pattern of in situ hybridization is shown in Figure $9 B$. What is unknown at present is whether such a gradient would also be found in protein expression, but that will require the future generation of a specific antibody to the $\beta$ protein.

The prediction of cochlear location for $\alpha$ splice variants is less definitive. Each alternative exon contributes to widely separated channels depending on the presence of $\beta$ subunits. In addition, each exon may represent functionally distinct channels depending on which other alternative exons are present in that transcript. So for instance the $\alpha_{4}$ exon (SRKR) contributes to BK tuning at 1200 $\mathrm{Hz}$ when residing alone, but it is part of channels tuned to $950 \mathrm{~Hz}$ when combined with the 61 and 28 amino acid exons. Although the effects of splicing alone are modest, the overall prediction from these studies is that individual exons could be found in hair cells from large portions of the sensory epithelium, as has indeed been shown in chicks (Navaratnam et al., 1997; Rosenblatt et al., 1997) and turtles (Jones et al., 1998).

\section{DISCUSSION}

Co-expression of avian hair cell slo- $\alpha$ splice variants with an accessory $\beta$ subunit slowed channel kinetics and increased the voltage sensitivity when compared with these features of the $\alpha$-only channels. These observations agree with those made in studies of mammalian slo channels (McManus et al., 1995; Vogalis et al., 1996; Saito et al., 1997), including the fact that $\beta$ modulation of steady-state gating was only evident for calcium concentrations $>200 \mathrm{~nm}$ (Meera et al., 1996). At calcium concentrations $1 \mu \mathrm{M}$ or higher, $\beta$ co-expression caused a negative shift of the half-activation voltage of hair cell slo channels, as though the effective calcium concentration had been raised. Although this can be quantified as an increase in the apparent calcium sensitivity, the effect of $\beta$ was not equivalent to an increase in calcium concentration. This is evident by considering the effects on activation kinetics. Higher calcium increases both the open probability and the rate of activation (Jiang et al., 1997), whereas $\beta$ co-expression slowed activation rates while increasing steadystate activation (compare activation currents in Figs. $3 A, 4 A$ ) (Jones et al., 1999). A related distinction between $\beta$ and calcium effects on open probability and gating kinetics also was observed in single-channel studies (Nimigean and Magleby, 1999). The principal action of the $\beta$ subunit was to increase channel burst duration; this stabilization of the bursting state resulted in an apparent increase in calcium sensitivity.

Although the present studies were not designed to determine the mechanism of $\beta$ modulation, some insights are provided by consideration of its interaction with alternative splicing of the $\alpha$ subunit. These alternative exons are in the $\mathrm{C}$ terminus of the $\mathrm{BK}$ channel that is thought to possess the calcium binding region of the protein (Wei et al., 1994; Schreiber and Salkoff, 1997; Schreiber et al., 1999). Splice variants containing the 61 amino acid exon $\left(\alpha_{61}, \alpha_{4-61-28}\right)$ had higher calcium affinity and slower deactivation kinetics. Splice variants without that exon $\left(\alpha_{0}, \alpha_{4}\right)$ had lower calcium affinity and more rapid deactivation kinetics. [This is reminiscent of the relationship of "indel length" to activation parameters observed in turtle slo channels (Jones et al., 1999)]. When combined with $\beta$ subunits, splice variants containing the 61 exon underwent a 20 -fold slowing of kinetics, but calcium affinity was altered at most twofold. In contrast, channels without the 61 exon had lesser changes in kinetics (10-fold slowing) but greater increases in calcium affinity (approximately fivefold). Clearly, the quantitative effect of the $\beta$ subunit is also influenced by the exon structure of the $\alpha$ subunit with which it combines. In short, $\beta$ altered the relationship between calcium affinity and kinetics, resulting in a convergence of calcium affinities but a dispersal of gating kinetics among these $\alpha$ splice variants. The net result is that $\beta$-combined channels exhibit a wider range of gating kinetics near the resting membrane potential than would $\alpha$-only channels.

It is important to point out that of the cDNAs used here, only $\alpha_{0}$ is known to exist as a functional mRNA because it was cloned as a complete transcript from a cochlear cDNA library. In addition, however, the $\alpha_{4-61-28}$ exon combination was amplified and sequenced from the cochlear duct, as well as from individual hair cells, and so is a naturally occurring splice variant. It is worth noting that the kinetics of this channel were slowed 20 -fold by $\beta$ combination, whereas the calcium affinity was least changed of all four splice variants (Fig. 8). 


\section{$\boldsymbol{\beta}$ Modulation and tonotopic gradients}

The two mechanisms of generating kinetic diversity in BK channels, alternative splicing and $\beta$ modulation, seem to act via separate mechanisms that complement rather than confound one another. Addition of the 61 amino acid exon at splice site 4 caused an increase in calcium sensitivity and slowed the deactivation kinetics, as did the addition of $\beta$ to $\alpha_{0}$. However, when $\alpha_{61}$ was combined with $\beta$ subunits, a still higher sensitivity to calcium was achieved, as was a more dramatic slowing of the deactivation rate. The change in the deactivation time constant between splice variants was in fact exaggerated by the addition of $\beta$ (2.5-fold between $\alpha_{0}$ and $\alpha_{61}$ versus fivefold between $\alpha_{0} \beta$ and $\left.\alpha_{61} \beta\right)$. Thus, the $\beta$ subunit acts as a molecular lever, extending the specific gating characteristics of each BK channel to a longer time frame. This is consistent with the effect of the bovine $\beta$ subunit on turtle hair cell slo- $\alpha$ channels observed by Jones et al. (1999). Therefore, both mechanisms, alternative splicing and $\beta$ modulation, are available for producing kinetic heterogeneity in hair cell BK channels.

A model for chick electrical tuning derived by extending the kinetic properties of turtle hair cell BK channels to higher frequencies suggests that this mechanism could operate at up to 4000 $\mathrm{Hz}$ (Wu et al., 1995). However, the BK channels described here predict electrical tuning frequencies up to only $1250 \mathrm{~Hz}$ (at $40^{\circ} \mathrm{C}$ ). Still higher frequencies might be enabled by yet unknown BK subtypes. It is clear that additional splice variants of chick slo- $\alpha$ remain to be characterized (Navaratnam et al., 1997; Rosenblatt et al., 1997) and might include shorter forms with faster gating kinetics like those described in turtle (Jones et al., 1999). Also, other $\beta$ subunits with different function could exist, as suggested by the significant differences in sequence and effect between avian and mammalian $\beta$ as well as by novel mammalian $\beta$ subunits (Wallner et al., 1999).

What regulatory mechanisms lead to the tonotopic distribution of channel kinetics that underlies electrical tuning? The present results suggest a process whereby both transcriptional and posttranscriptional gene regulation together generate the gradients in channel kinetics of avian cochlear hair cells. How are these different gene products combined to produce a unique tuning frequency in each hair cell? In situ hybridization in the quail basilar papilla showed that the $\beta$ subunit is expressed in a gradient such that apical (low-frequency) hair cells have higher levels than do basal hair cells (Ramanathan et al., 1999). Thus, one possibility is that $\beta$ subunits are "titrated" into a population of slo channels to produce different tuning frequencies. Co-expression of turtle slo channels with bovine $\beta$ subunits showed that the effects of $\beta$ combination were "all or none," resulting in channels that either were $\alpha$-only in behavior or showed the entire $\beta$ effect (Jones et al., 1999). Partial effects of $\beta$ were not observed on these channels. Thus, a $\beta$ expression gradient along the length of the cochlea might result in hair cells in which the ratio of $\alpha$ to $\alpha \beta$ channels varies. How might such "chimeric" hair cells behave? Can a kinetically heterogeneous population of channels produce unique tuning properties in one hair cell? The same question applies to the expression of multiple $\alpha$ splice variants in single hair cells, although here the kinetic differences between channels are not so dramatic. Answers to these questions can be provided by quantitative models of hair cells based on the properties of channels described here.

\section{REFERENCES}

Adelman JP, Shen KZ, Kavanaugh MP, Warren RA, Wu YN, Lagrutta A, Bond CT, North RA (1992) Calcium-activated potassium channels expressed from cloned complementary DNAs. Neuron 9:209-216.

Art JJ, Fettiplace R (1987) Variation of membrane properties in hair cells isolated from the turtle cochlea. J Physiol (Lond) 385:207-242.

Art JJ, Wu YC, Fettiplace R (1995) The calcium-activated potassium channels of turtle hair cells. J Gen Physiol 105:49-72.

Atkinson NS, Robertson GA, Ganetzky B (1991) A component of calcium-activated potassium channels encoded by the Drosophila slo locus. Science 253:551-555.

Bers DM, Patton CW, Nuccitelli R (1994) A practical guide to the preparation of $\mathrm{Ca} 2+$ buffers. Methods Cell Biol 40:3-29.

Butler A, Tsunoda S, McCobb DP, Wei A, Salkoff L (1993) mSlo, a complex mouse gene encoding "maxi" calcium-activated potassium channels. Science 261:221-224.

Chen L, Salvi R, Shero M (1994) Cochlear frequency-place map in adult chickens: intracellular biocytin labeling. Hear Res 81:130-136.

Crawford AC, Fettiplace R (1980) The frequency selectivity of auditory nerve fibres and hair cells in the cochlea of the turtle. J Physiol (Lond) 306:79-125.

Crawford AC, Fettiplace R (1981) An electrical tuning mechanism in turtle cochlear hair cells. J Physiol (Lond) 312:377-412.

Cui J, Cox DH, Aldrich RW (1997) Intrinsic voltage dependence and $\mathrm{Ca} 2+$ regulation of mslo large conductance $\mathrm{Ca}$-activated $\mathrm{K}+$ channels. J Gen Physiol 109:647-673.

Dworetzky SI, Boissard CG, Lum-Ragan JT, McKay MC, Post-Munson DJ, Trojnacki JT, Chang CP, Gribkoff VK (1996) Phenotypic alteration of a human BK (hSlo) channel by hSlo beta subunit coexpression: changes in blocker sensitivity, activation/relaxation and inactivation kinetics, and protein kinase A modulation. J Neurosci 16:4543-4550.

Fettiplace R, Fuchs PA (1999) Mechanisms of hair cell tuning. Annu Rev Physiol 61:809-834.

Fuchs PA, Evans MG (1990) Potassium currents in hair cells isolated from the cochlea of the chick. J Physiol (Lond) 429:529-551.

Fuchs PA, Nagai T, Evans MG (1988) Electrical tuning in hair cells isolated from the chick cochlea. J Neurosci 8:2460-2467.

Gummer AW, Smolders JW, Klinke R (1987) Basilar membrane motion in the pigeon measured with the Mossbauer technique. Hear Res 29:63-92.

Hudspeth AJ, Lewis RS (1988) Kinetic analysis of voltage- and iondependent conductances in saccular hair cells of the bull-frog, Rana catesbeiana. J Physiol (Lond) 400:237-274.

Issa NP, Hudspeth AJ (1994) Clustering of Ca2+ channels and Ca(2+)activated $\mathrm{K}+$ channels at fluorescently labeled presynaptic active zones of hair cells. Proc Natl Acad Sci USA 91:7578-7582.

Jiang GJ, Zidanic M, Michaels RL, Michael TH, Griguer C, Fuchs PA (1997) CSlo encodes calcium-activated potassium channels in the chick's cochlea. Proc R Soc Lond B Biol Sci 264:731-737.

Jones EM, Laus C, Fettiplace R (1998) Identification of $\mathrm{Ca}(2+)$ activated $\mathrm{K}+$ channel splice variants and their distribution in the turtle cochlea. Proc R Soc Lond B Biol Sci 265:685-692.

Jones EM, Gray-Keller M, Fettiplace R (1999) The role of Ca2+activated $\mathrm{K}+$ channel spliced variants in the tonotopic organization of the turtle cochlea. J Physiol (Lond) 518:653-665.

Jones SM, Jones TA (1995) The tonotopic map in the embryonic chicken cochlea. Hear Res 82:149-157.

Knaus HG, Folander K, Garcia-Calvo M, Garcia ML, Kaczorowski GJ, Smith M, Swanson R (1994) Primary sequence and immunological characterization of beta-subunit of high conductance $\mathrm{Ca}(2+)$-activated $\mathrm{K}+$ channel from smooth muscle. J Biol Chem 269:17274-17278.

Lustig L, Hiel H, Fuchs PA (1999) Vestibular hair cells of the chick express the nicotinic acetylcholine receptor subunit $\alpha 9$. J Vestib Res 9:359-367.

Manley GA, Brix J, Kaiser A (1987) Developmental stability of the tonotopic organization of the chick's basilar papilla. Science 237:655-656.

Marrion NV, Tavalin SJ (1998) Selective activation of Ca2+-activated $\mathrm{K}+$ channels by co-localized $\mathrm{Ca} 2+$ channels in hippocampal neurons. Nature 395:900-905.

McManus OB, Helms LM, Pallanck L, Ganetzky B, Swanson R, Leonard 
RJ (1995) Functional role of the beta subunit of high conductance calcium-activated potassium channels. Neuron 14:645-650.

Meera P, Wallner M, Jiang Z, Toro L (1996) A calcium switch for the functional coupling between alpha (hslo) and beta subunits (Kv,cabeta) of maxi K channels. FEBS Lett 385:127-128.

Michael TH, Ramanathan K, Jones EMC, Art JJ, Fettiplace R, Fuchs PA (1997) Functional expression of cochlear slo potassium channels in HEK 293 cells and Xenopus oocytes. Biophys J 72:A352.

Navaratnam DS, Bell TJ, Tu TD, Cohen EL, Oberholtzer JC (1997) Differential distribution of $\mathrm{Ca} 2+$-activated $\mathrm{K}+$ channel splice variants among hair cells along the tonotopic axis of the chick cochlea. Neuron 19:1077-1085.

Nimigean CM, Magleby KL (1999) The beta subunit increases the $\mathrm{Ca}^{2+}$ sensitivity of large conductance $\mathrm{Ca}^{2+}$-activated potassium channels by retaining the gating in the bursting states. J Gen Physiol 113:425-440.

Oberst C, Weiskirchen R, Hartl M, Bister K (1997) Suppression in transformed avian fibroblasts of a gene (CO6) encoding a membrane protein related to mammalian potassium channel regulatory subunits. Oncogene 14:1109-1116.

Ramanathan K, Michael TH, Jiang G, Hiel H, Fuchs PA (1999) A molecular mechanism for electrical tuning of cochlear hair cells. Science 283:215-217.

Roberts WM, Jacobs RA, Hudspeth AJ (1990) Colocalization of ion channels involved in frequency selectivity and synaptic transmission at presynaptic active zones of hair cells. J Neurosci 10:3664-3684.

Robitaille R, Adler EM, Charlton MP (1993) Calcium channels and calcium-gated potassium channels at the frog neuromuscular junction. J Physiol (Paris) 87:15-24.

Rosenblatt KP, Sun ZP, Heller S, Hudspeth AJ (1997) Distribution of $\mathrm{Ca} 2+$-activated $\mathrm{K}+$ channel isoforms along the tonotopic gradient of the chicken's cochlea. Neuron 19:1061-1075.

Saito M, Nelson C, Salkoff L, Lingle CJ (1997) A cysteine-rich domain defined by a novel exon in a slo variant in rat adrenal chromaffin cells and PC12 cells. J Biol Chem 272:11710-11717.
Schermuly L, Klinke R (1985) Change of characteristic frequency of pigeon primary auditory afferents with temperature. J Comp Physiol 156:209-211.

Schreiber M, Salkoff L (1997) A novel calcium-sensing domain in the BK channel. Biophys J 73:1355-1363.

Schreiber M, Yuan A, Salkoff L (1999) Transplantable sites confer calcium sensitivity to BK channels. Nat Neurosci 2:416-421.

Sonderegger C (1998) Conditional cell transformation by a doxycyclinecontrolled v-myc allele. PhD thesis, Institute of Biochemistry, University of Innsbruck.

Tseng-Crank J, Foster CD, Krause JD, Mertz R, Godinot N, DiChiara TJ, Reinhart PH (1994) Cloning, expression, and distribution of functionally distinct $\mathrm{Ca}(2+)$-activated $\mathrm{K}+$ channel isoforms from human brain. Neuron 13:1315-1330.

Vogalis F, Vincent T, Qureshi I, Schmalz F, Ward MW, Sanders KM, Horowitz B (1996) Cloning and expression of the large-conductance $\mathrm{Ca}(2+)$-activated $\mathrm{K}+$ channel from colonic smooth muscle. Am J Physiol 271:G629-639.

Wallner M, Meera P, Toro L (1996) Determinant for beta-subunit regulation in high-conductance voltage-activated and $\mathrm{Ca}(2+)$-sensitive $\mathrm{K}+$ channels: an additional transmembrane region at the $\mathrm{N}$ terminus. Proc Natl Acad Sci USA 93:14922-14927.

Wallner M, Meera P, Toro L (1999) Molecular basis of fast inactivation in voltage and $\mathrm{Ca}^{2+}$-activated $\mathrm{K}^{+}$channels: a transmembrane $\beta$-subunit homolog. Proc Natl Acad Sci USA 96:4137-4142.

Wei A, Solaro C, Lingle C, Salkoff L (1994) Calcium sensitivity of BK-type $\mathrm{KCa}$ channels determined by a separable domain. Neuron 13:671-681.

Wu YC, Art JJ, Goodman MB, Fettiplace R (1995) A kinetic description of the calcium-activated potassium channel and its application to electrical tuning of hair cells. Prog Biophys Mol Biol 63:131-158.

Wu YC, Fettiplace R (1996) A developmental model for generating frequency maps in the reptilian and avian cochleas. Biophys $\mathbf{J}$ 70:2557-2570. 